\title{
Genitalic changes related to oviposition in the terrestri- al isopod Armadillidium vulgare (Latreille, 1804)
}

Sachiko Suzuki

\begin{abstract}
Females of the terrestrial isopod Armadillidium vulgare (Latreille, 1804) possess a pair of cuticular genitalia in the oviducts, which are renewed at each non-parturial molt. The genitalia consist of a distal segment surrounding the gonopore, and a cuticular tube lining the lumen of the oviduct. At parturial molt, however, adult females do not produce new genitalia. Their genitalia are only modified. Moreover, egg-carrying females possess new genitalia after each parturial molt. The timing of formation of new genitalia after the parturial molt is still indistinct. The process was investigated morphologically around the time of oviposition. After the parturial molt, females retain only the cuticular tubes of the old genitalia in the oviducts. Several hours after molting and just before oviposition, these cuticular tubes are cast off from the oviducts and a pair of oopores opens on the coxal plate of the fifth perionite. After oviposition, the oopores become gradually unobservable with time. New genitalia are not present in the oviducts until at least 24 hours after the parturial molt. The reconstruction of new genitalia seems to be associated with the disappearance of the oopores.
\end{abstract}

\section{Introduction}

Major episodes of the reconstructive process of the female genitalia during the reproductive cycle have been described for the first time in the terrestrial isopod, Armadillidium vulgare by Suzuki (2001). Female genitalia occur in two states: a nonreproductive state and a reproductive state (Suzuki, 2001, 2002; Suzuki \& Ziegler, 2005). Light microscopic studies show structural conversion of the genitalic states depending on the reproductive condition (Suzuki, 2001, 2002). Females with immature ovaries cast off the old genitalia together with the old exoskeleton of the posterior body region and form new genitalia of the non-reproductive state during non-parturial molt. Females with mature ovaries cast off only the distal segments together with the old exoskeleton and continue to hold the cuticular tubes (Suzuki \& Ziegler, 2005) of the old genitalia in the oviducts at the parturial molt (Suzuki, 2002). That is, new genitalia of non-reproductive state are generated at the non-parturial molt. New genitalia of reproductive state are not generated at the parturial molt (Suzuki, 2001). It is unknown when egg-carrying females can reconstruct new genitalia after oviposition. In order to elucidate the development of the new genitalia, morphological observations on the structural changes of the genitalia associated with oviposition were carried out.

\section{Materials and Methods}

Individuals of Armadillidium vulgare were collected in Yokohama, Japan, in April, during the reproductive period. Adult females, $10-12 \mathrm{~mm}$ in body length, were used in the present study. Groups of several females and two adult males $(12 \mathrm{~mm})$ were 


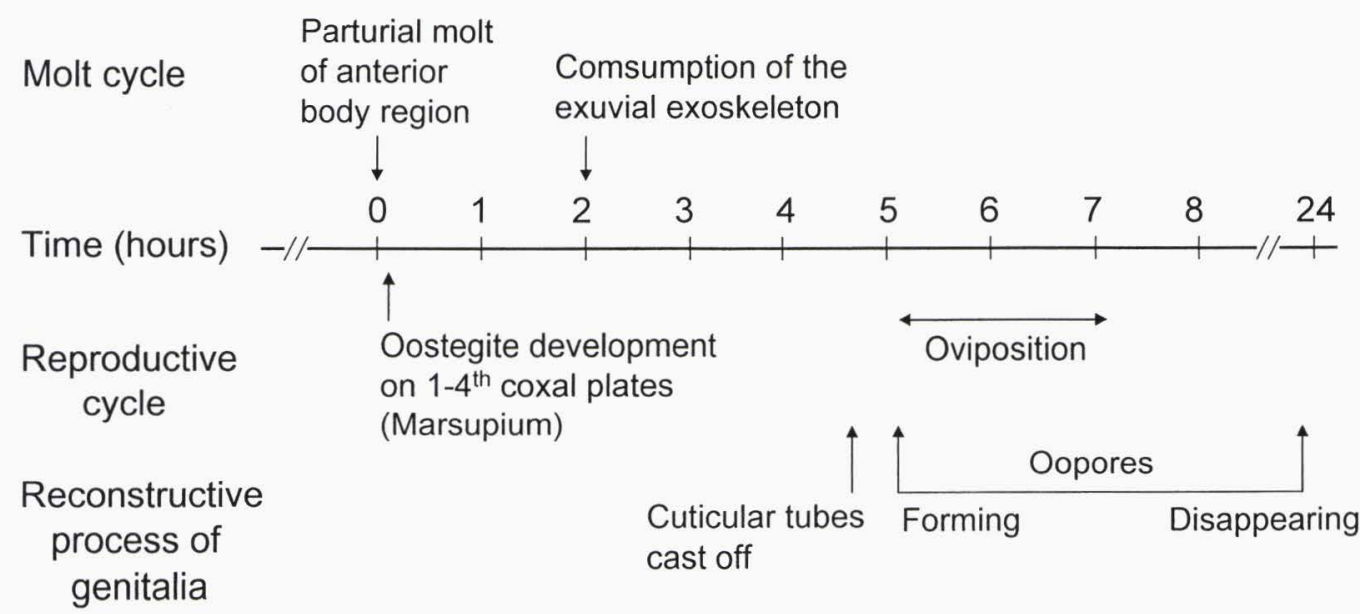

Fig. 1. Time schedule of the reconstructive process of the female genitalia which is restricted to the time around oviposition in Armadillidium vulgare. The relationship between the reconstructive process of genitalia, female reproductive cycle and molt cycle is shown. Time is plotted against 0 hours when females complete the exuviation of the anterior body region in the parturial molt.

maintained in petri dishes $(8.5 \mathrm{~cm}$ in diameter) with moistened soil, and were fed on decayed leaves and rat food. They were reared at $25 \pm 2^{\circ} \mathrm{C}$ in the laboratory; lighting was not controlled.

Females of this species form sternal calcium carbonate $\left(\mathrm{CaCO}_{3}\right)$ deposits before molting. The shape of the $\mathrm{CaCO}_{3}$ deposits with a diamond opening (Moreau \& Rigaud, 2002) was used to estimate the time of parturial molt (Suzuki, 2002). When females started undergoing parturial molting in their posterior body region, they were reared separately and daily observations were made individually on 80 females, both visually and microscopically. Individuals were sacrificed at intervals of one hour until 24 hours after the completion of exuviation of the anterior body region. The female reproductive sys-

Fig. 2. Ventral views of the female reproductive system dissected out 2 hours (see Fig. 1) after the parturial molt. (A): A pair of ovaries filled with mature oocytes. (B): Enlargement of the left oviduct in (A), showing that the cuticular tube is retained and that spermatozoa are stored in the oviduct. ct, cuticular tube; mo, mature oocyte; od, oviduct; ov, ovary; s, sperm; sr; seminal receptacle; scale, $500 \mu \mathrm{m}$,.
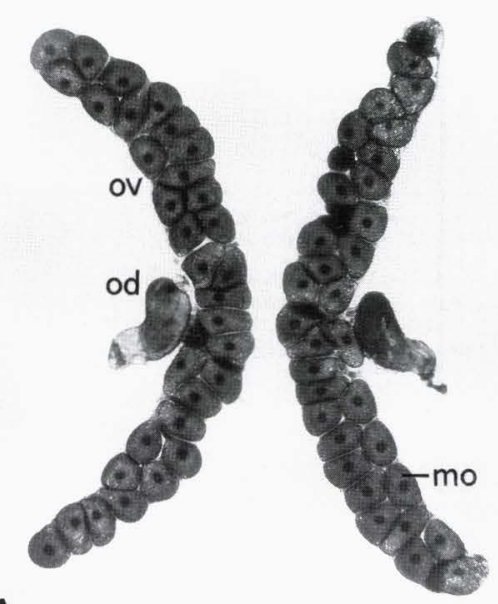

A -

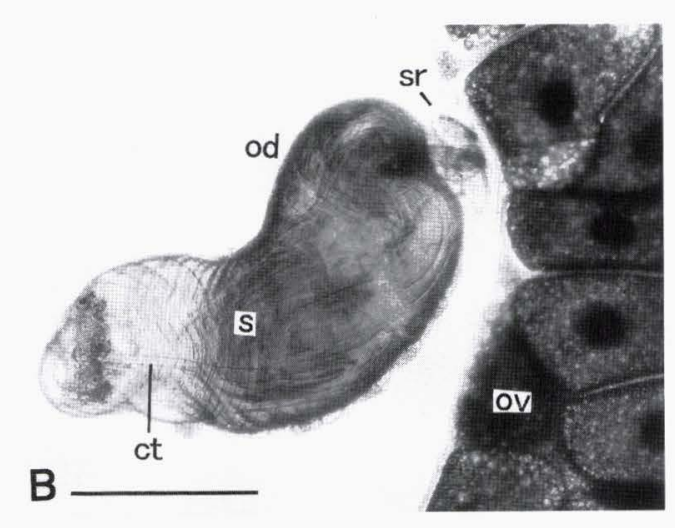


A

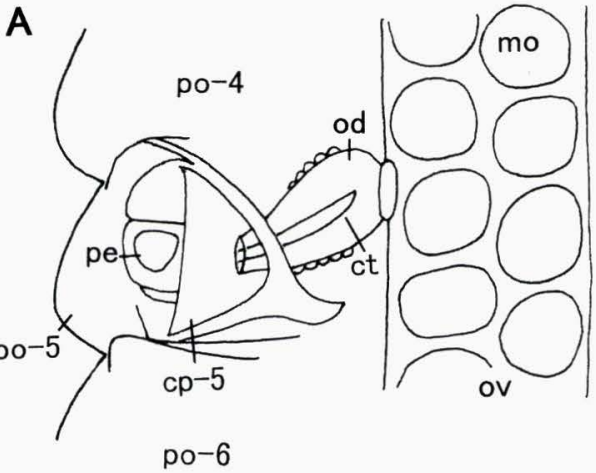

B

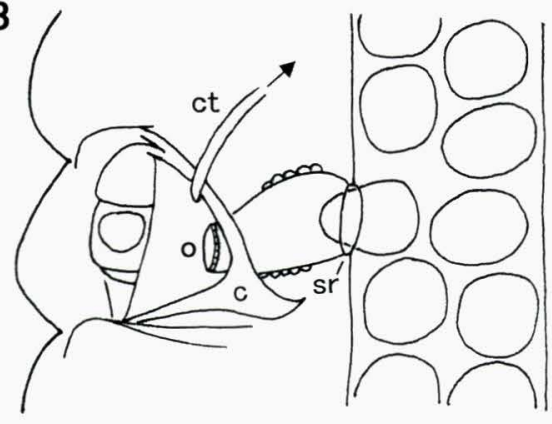

C

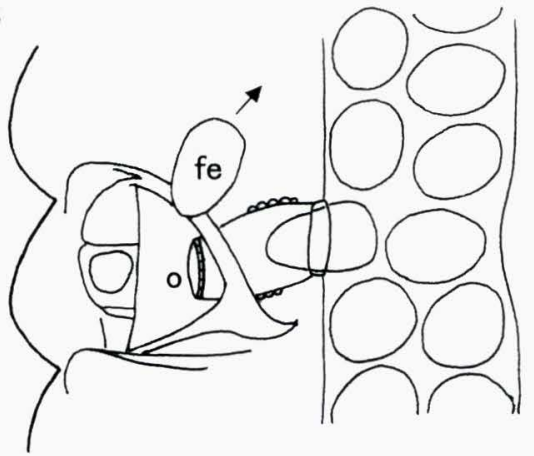

D

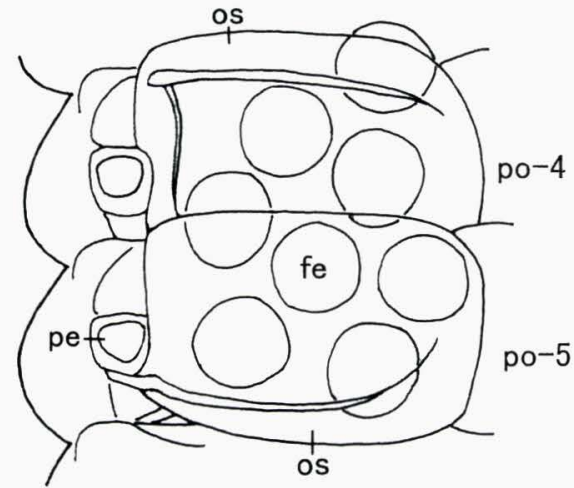

Fig. 3. A schematic representation of the female reproductive process between parturial molt and oviposition. Each diagram shows the ventral view of the reproductive system of the right side of a female at 0 hours (A), 4 hours (B), 5 hours (C) and 10 hours (D) after the parturial molt. The marsupium (oostegites) is removed completely in (A-C). (A): The cuticular tube is retained in the oviduct at the parturial molt. (B): The cuticular tube is cast off from the oviduct and the oopore is formed. (C): Fertilized eggs are transferred from the ovary through the oopore into the marsupium during oviposition. (D): All eggs are extruded into the marsupium after oviposition. arrow, direction of movement; c, cuticle; cp-5, coxal plate of the fifith pereionite; ct, cuticular tube; fe, fertilized egg; mo, mature oocyte; o, oopore; od, oviduct; os, oostegite; ov, ovary; pe, pereopod; po-4, 5 and 6 , fourth, fifth and sixth pereionites; sr, seminal receptacle.

tem was dissected out in crustacean physiological saline under a dissecting microscope. The structure of the genitalia was investigated at four different times during the 24 hours after a parturial molt: after parturial molt, before oviposition, during oviposition and after oviposition. Each time of dissection and observation was plotted against the completion of exuviation of the anterior body region in a parturial molt, as shown in Fig. 1.

For histological observations of the female reproductive system, whole animals were fixed in Bouin's solution for 24 hours and processed using standard paraffin embedding methods. Paraffin-embedded females were sectioned at $10 \mu \mathrm{m}$ and stained with Mayer's hematoxylin and eosin.

\section{Results}

\section{After parturial molt ( $0-3$ hours)}

Adult females, $12 \mathrm{~mm}$ in body length, have mature ovaries of $8-10 \mathrm{~mm}$ in length. Their ovaries are filled with mature oocytes (550-600 $\mu \mathrm{m}$ in diameter) and their oviducts are filled with sperm (Fig. 2A, B). At the 


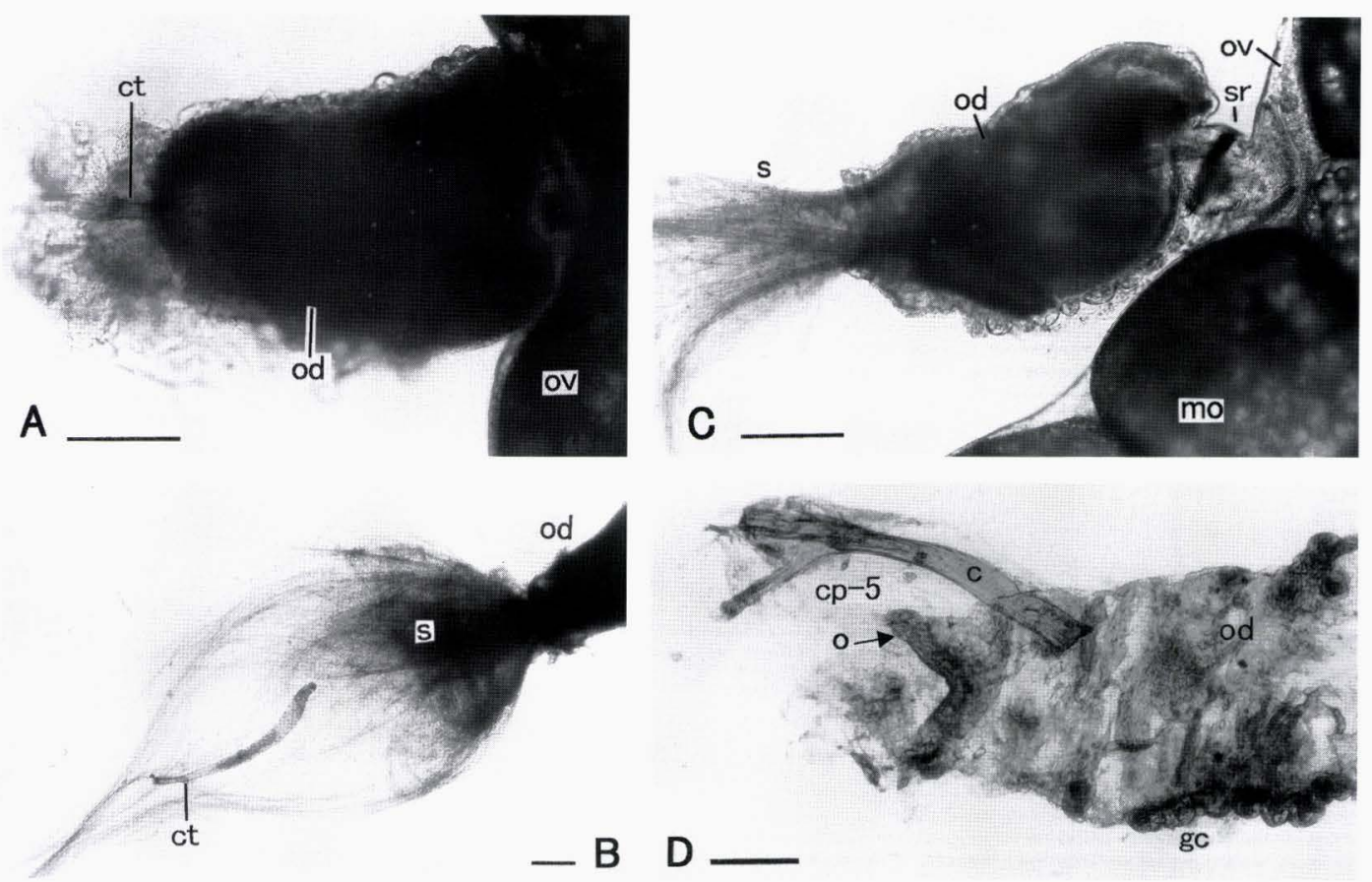

Fig. 4. Ventral views of the female reproductive system dissected out before oviposition from the right side of a female, 4 hours (A, B) and 5 hours (C, D) after the parturial molt. (A): Cuticular tube retained in the oviduct. (B): Cuticular tube detached from the oviduct together with sperm at the time of dissection. (C): Oviduct and ovary dissected out without the fifth coxal plate, showing that sperm flow out from the oviduct due to ovarian constriction. (D): Oviduct dissected with the fifth coxal plate, indicating that the oopore (arrow) is present on the coxal plate of the fifth pereionite. Spermatozoa in the oviduct are extruded out. c, cuticle; cp-5, coxal plate of the fifth pereionite; ct, cuticular tube; gc, gland cell; mo, mature oocyte; o, oopore; od, oviduct; ov, ovary; s, sperm; sr, seminal receptacle; scale, 200 $\mu \mathrm{m}$.

time of parturial molt in the posterior body region, females cast off the distal segments of the old genitalia together with the old exoskeleton and leave behind the cuticular tube of the old genitalia in the oviducts. They form oostegites on the fifth coxal plate (Calman, 1909) immediately after the posterior molting. Following the exuviation of their posterior body region, about one day later they undergo parturial molting in the anterior body region. Four pairs of oostegites form on the $1-4^{\text {th }}$ coxal plates (Fig. 1). Five pairs of oostegites in total develop a marsupium between them and the ventral surface of the $1-5^{\text {th }}$ pereionites. After completion of the anterior molt, the remaining cuticular tubes are still retained in the oviducts (Fig. 2B) and attached to the fifth coxal plate (Fig. 3A). Two hours after molting, the females consume the exuvial exoskeletons of the anterior body region within one hour (Fig. 1). New genitalia in the reproductive state are not present in the oviducts.

\section{Before oviposition (4-5 hours)}

The epithelial cells (Suzuki \& Ziegler, 2005) of the oviducts start to be contracted and the oviducts gradually become shorter (Fig. 4A). About four hours after the parturial molt, the retained cuticular tubes are still present within the oviduct (Fig. 4A) but are less firmly attached to the coxal plate of the fifth pereionite. At the time of dissection of 

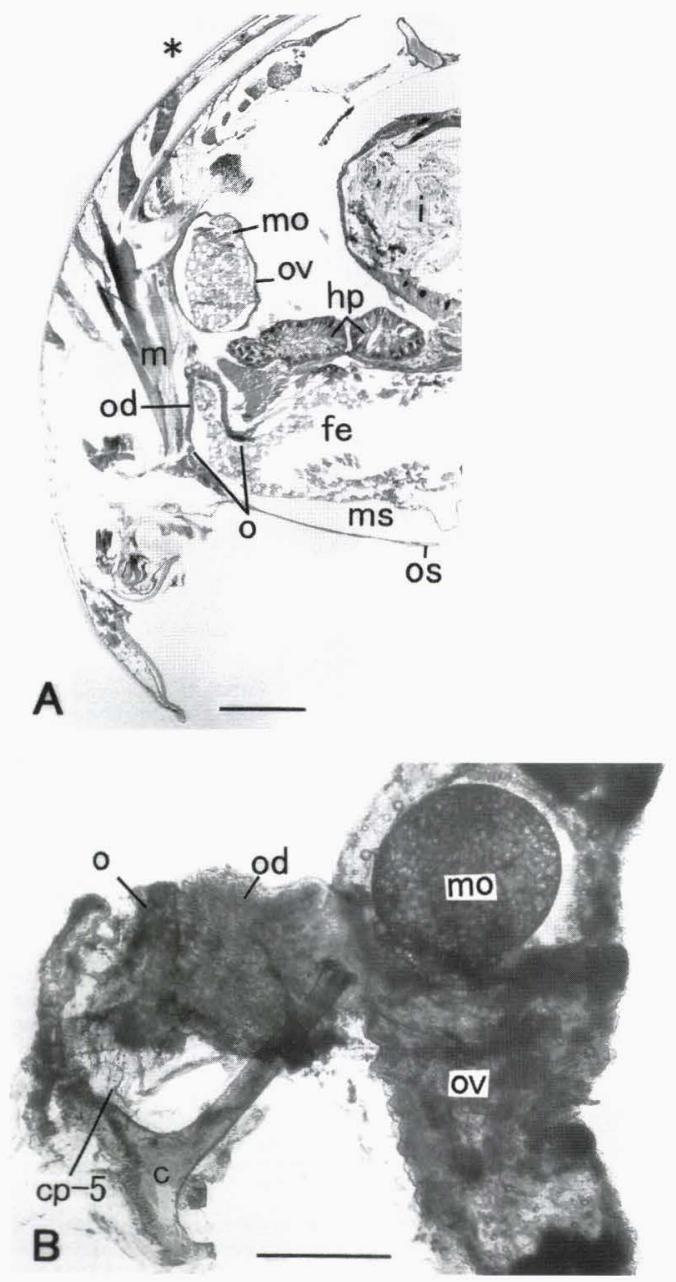

Fig. 5. Female reproductive system during oviposition (about 7 hours), showing existence of a mature oocyte in the ovary and the oopore. (A): Transverse section of the left side of the fifth pereionite in paraffin section. (B): Ventral overview of the reproductive system dissected out with the fifth coxal plate from the right side of a female. The coxal plate is positioned opposite to the oviduct after dissection. *, dorsal surface; c, cuticle; cp-5, coxal plate of the fifth pereionite; fe, fertilized egg; hp, hepatopancreas; i, intestine; $\mathrm{m}$, muscle; mo, mature oocyte; ms, marsupium; o, oopore; od, oviduct; os, oostegite; ov, ovary; scale, $500 \mu \mathrm{m}$.

the reproductive system, the cuticular tubes are easily detached and removed from the oviducts together with sperm (Fig. 4B). The isolated ovaries contract continuously in saline with regular movements and spermatozoa emerge from the oviduct (Fig. 4C). Spermatozoa are filamentous, about $1 \mathrm{~mm}$ in length and non-motile. About $30 \mathrm{~min}$ before oviposition, the cuticular tubes are pushed out, probably by the internal pressure of the contractile ovaries. They move from the oviducts into the marsupium (Figs. 1, 3B). Shortly afterward, the oopores open on the coxal regions (Calman, 1909; Wilson, 1991) near the fifth pereopod (Figs. 1, 3B). The oopores are formed at the distal part of the oviducts and firmly connected to the fifth coxal plate (Fig. 4D). The position of the oopores is the same as that of the distal segments of the old genitalia. The oopores reach a size of $400-500 \mu \mathrm{m}$ in diameter (Fig. 4D). Before oviposition, females show limited movements without walking.

\section{During oviposition (5-7 hours)}

The epithelial cells of the ovaries are strongly contracted in saline and mature oocytes are transferred from the ovary into the oviduct (not shown). Five hours after the parturial molt and shortly after oopore opening, the females curl their bodies into a hemispherical shape and strain themselves at regular intervals. Females retain spermatozoa in the oviducts (Figs. 2B, 4C), and in the seminal receptacles (Figs. 2B, 4C). When mature oocytes (Fig. 5A, B) are sent out from the ovaries into the oviducts, they pass through these sperm storages. The fertilized eggs (Figs. 3C, 5A) are extruded smoothly and successively through the oopores into the marsupium by the force of the contractile ovaries. The females complete oviposition within about two hours (Fig.1).

\section{After oviposition (7-24 hours)}

The females soon start walking around. Their marsupium is filled with fertilized eggs (Fig. 3D). After oviposition, the spent ovaries, having a length of about $4.0 \mathrm{~mm}$, are successively shrinking and show a wrinkled state for a while (Fig. 6A, B). The oopores 

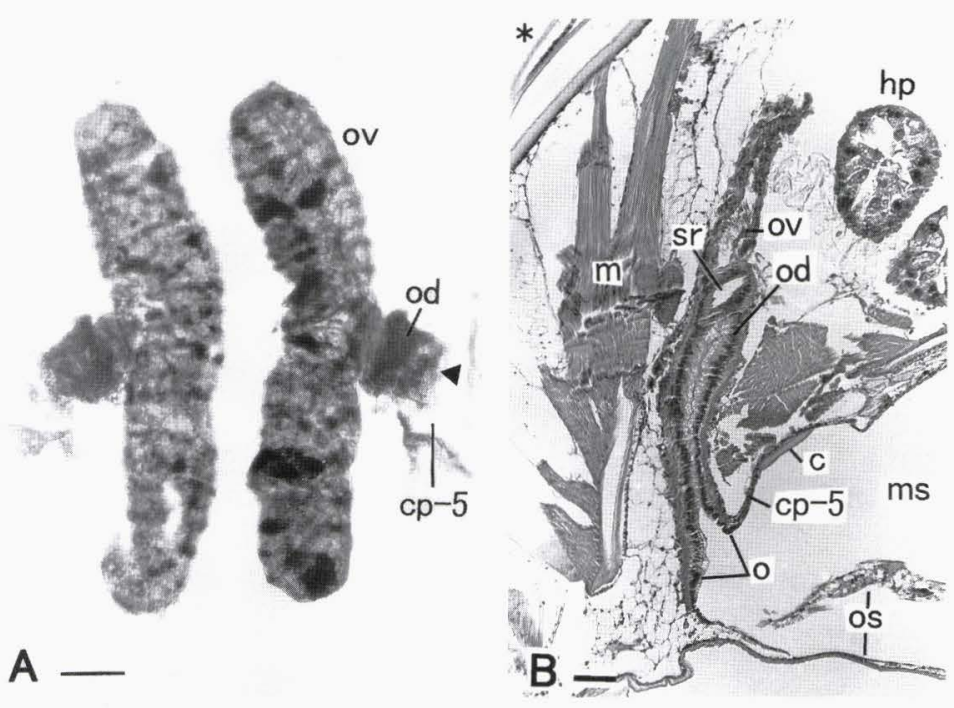

Fig.6. Female reproductive system after oviposition. (A): Ventral views of the female reproductive system dissected out with the fifth coxal plate 10 hours after the parturial molt, showing shrinking ovaries and oopore (arrow head). (B): Left side of the fifth pereionite in transverse paraffin section at 20 hours after molting, showing the shrinking ovary and the existence of the oopore. *, dorsal surface; c, cuticle; cp-5, coxal plate of the fifth pereionite; hp, hepatopancreas; $m$, muscle; ms, marsupium; o, oopore (arrow head); od, oviduct; os, oostegite; ov, ovary; sr, seminal receptacle; scale, $500 \mu \mathrm{m}$.

are still present on the fifth coxal plate (Fig. $6 \mathrm{~A}, \mathrm{~B})$, but become gradually unobservable with time (Fig. 1). New genitalia in the reproductive state are not observed until 24 hours after the parturial molt (Figs. 1,6B).

\section{Discussion}

\section{Genitalia of Armadillidium vulgare}

Morphological diversity of female genitalia in the isopod crustaceans has been reported (Calman, 1909; Vandel, 1925; Veuille, 1978; Lincoln, 1985; Wilson, 1984, 1986, 1991; Wägele, 1990, 1992; Suzuki, 2001, 2002). The genitalia of Armadillidium vulgare are present in the lumen of the oviducts consisting of a cuticular tube and a distal segment (Suzuki \& Ziegler, 2005). The cuticular tube, which was called a spermathecal duct (Wilson, 1991) in previous publications (Suzuki, 2001, 2002), is a tubelike structure lining the middle region of the oviduct. The spermathecal duct found in the janiroidean Asellota has a vaginal-like struc- ture, that is separated from the oviduct and opening on the dorsal surface for copulation (Wilson, 1986, 1991). The ultrastructural studies of $A$. vulgare show the cuticular tube is present in the oviduct and lacking a separate duct (Suzuki \& Ziegler, 2005). Therefore, I avoided using the term spermathecal duct in this species. The distal segment is a distal region of the genitalia and surrounding the gonopore. In this species the distal region was called a copulatory opening (Suzuki, 2001, 2002), however, the opening may be confused with the term, gonopore. I also avoided to use the term, copulatory opening (Suzuki \& Ziegler, 2005).

\section{Function of retained cuticular tubes}

After the parturial molt, the cuticular tubes of the old genitalia are successively retained in the oviducts. If they were to be present for a long time in the oviducts, mature oocytes would not be able to pass through the oviducts during oviposition. In 
fact, just prior to oviposition they are pushed out from the oviducts into the marsupium. This phenomenon may play an important role in successful fertilization. The distal region of the cuticular tube is presumably acting as a seal for leaving the oopore closed. In many isopod species, the spermatheca (Wilson, 1991) is the sperm-storing site within the oviduct and internal insemination is common (De Luca et al., 1987; Wilson, 1991; Warburg, 1993, Suzuki, 2001). In $A$. vulgare, mating takes place during the intermolt (Mead, 1976) and premolt (Moreau et al., 2002) stages that precede the parturial molt. Females store these spermatozoa in the enlarged oviducts called spermatheca by Suzuki (2001) and in the seminal receptacle (Suzuki \& Ziegler, 2005) that is the confluence of the oviduct with the ovary (Longo et al., 1998). The seminal receptacle of this species is capable to store spermatozoa for a long period (Suzuki \& Ziegler, 2005) and the enlarged oviduct (spermatheca) is a temporal storage for a short period from copulation till oviposition. Therefore, fertilization takes place when the mature oocytes pass through both sperm storages. If the cuticular tubes are cast off together with the distal segments at the time of the parturial molt, the oopores would be opened several hours before oviposition. In such a case, sperm stored in the oviducts and in the seminal receptacles would flow out through the oopores by pressure of the contractile ovaries before fertilization occurs internally. Just after molting, the bodies of A. vulgare individuals are very soft and their new exoskeletons require several hours for hardening. The present observations suggest that after molting females harbor the cuticular tubes within the oviduct in order to ensure the fertilization of eggs.

\section{Oopore development}

If the reproductive systems are dissected out from females without the fifth coxal plate just before oviposition, the oopores are not present at the distal part of the oviducts (Fig. 4C). The oopores are observed at the distal end of the oviducts when the reproductive organs are dissected out together with the fifth coxal regions (Fig. 4D). These observations mean that the epithelial cells of the oviducts form the oopores, connecting with the fifth coxal plate as shown in Fig. 6B.

In $A$. vulgare, the distal segmenta are cuticular lining surrounding the gonopores and receive the copulatory organs of males at mating. Distal segments are present throughout the lifetime of juvenile and adult females (Suzuki, unpublished), whereas, oopores is not cuticular structure (Suzuki, 2001; Figs. 5A, 6B) and are present for a short period of time for oviposition. The distal segment and the oopore are present at different phases of the genitalic development, and are situated at the similar position on the ventral surface of the body. Each has a different function in a single reproductive cycle. It seems likely that females replace the distal segments with the oopores for oviposition.

\section{Reconstructive process of female genitalia}

In the present study, the timing of development of new genitalia in the reproductive state could not be discovered light- microscopically. The formation probably occurs a long time after the parturial molt. It may be after the time when the oopores have completely disappeared following oviposition.

A relationship between the reproductive cycle and the molt cycle has been reported for many crustaceans (Adiyodi, 1985; Charniaux-Cotton \& Payen, 1988; Wilder et al., 1991; Okumura et al., 1992; De Kleijn et al., 1998; Bauer \& Abdalla, 2000). In A. vulgare, the reproductive cycle is also correlated with the molt cycle (Suzuki, 1987; Suzuki et al., 1989, 1996). As female genitalia of this species are cuticular structures, they are formed into new genitalia at each molt. At the parturial molt, the cuticular tubes of the old genitalia are separated from the distal segments (Suzuki, 2002). As a result, the distal segments are cast off together with the exuvial exoskeleton at molting, while the cuticular tubes are retained in the oviducts 
until the beginning of oviposition. Then, the oopores are formed. Correlation of these structural changes with the reproductive and molt cycles is observed, as shown in Fig. 1. However, additional studies will aid in understanding the development of genitalia in female $A$. vulgare.

\section{Acknowledgements}

The author expresses gratitude to Prof. Milton Fingerman (Tulane University) and Dr. Andreas Ziegler (Ulm University) for helpful comments and suggestions in reviewing the manuscript. The author also thanks Dr. Marcy Wilder and Dr. Vidya Jayasankar (Japan International Research Center for Agricultural Sciences) for critical reading of the manuscript. The author thanks Ms. Akiko Ueda (Cancer Center of Kanagawa Prefecture) for support in conducting the paraffin embedding and staining procedures in this study.

\section{Literature Cited}

Adiyodi, R.G.,1985. Reproduction and its control. In: D. E. Bliss \& L.H. Mantel (eds.), The Biology of Crustacea, Volume 9, 147-215. Academic Press, New York.

Bauer, R. T., \& Abdalla, J. H., 2000. Patterns of brood production in the grass shrimp Palaemonetes pugio (Decapoda: Caridea). Invertebrate Reproduction and Development, 38: 107-113.

Calman, W.T., 1909. The Isopoda. In: R. Lankester, (ed.), A Treatise on Zoology, 7, 196-223. Adam \& C. Black, London.

Charniaux-Cotton, H., \& Payen, G., 1988. Crustacean reproduction. In: H. Laufer \& R. G. H. Downer (eds.), Endocrinology of Selected Invertebrate Types, Volume 2, 279-303. Alan R. Liss, New York.

De Kleijn, D. P. V., Janssen, K. P. C., Waddy, S. L., Hegeman, R., Lai, W. Y., Martens, G. J. M., \& Van Herp, F., 1998. Expression of the crustacean hyperglycaemic hormones and the gonad-inhibiting hormone during the reproductive cycle of the female American lobster Homarus americanus. Journal of Endocrinology, 156: 291-298.

De Luca, V., Longo, G., Sottile, L., La Spina, G., \&
Viscuso, R., 1987. Scanning electron microscopy and histochemistry of the reproductive female system and sperm storage in Porcellio laevis Latreille (Isopoda Oniscoidea). Acta Embryologiae et Morphologiae Experimentalis, new series, 8: 243-255.

Lincoln, R. J., 1985. Deep-sea asellote isopods of the north-east Atlantic: the family Haploniscidae. Journal of Natural History, 19: 655-695.

Longo, G., Musmeci, R., Privitera, R., \& Sottile, L., 1998. Ultrastructural organization of seminal receptacle and sperm storage in Porcellio laevis Latreille (Crustacea: Isopoda Oniscidea). Tissue and Cell, 30: 464-474.

Mead, F., 1976. La place de'laccouplement dans le cycle de reproduction des isopodes terrestres (Oniscoidea). Crustaceana, 31: 27-41.

Moreau, J. \& Rigaud, T., 2002. The shape of calcium carbonate deposits as an external marker for female reproductive status in terrestrial isopods. Journal of Crustacean Biology, 22: 353-356.

- Seguin, S., Caubet, Y., \& Rigaud, T., 2002. Female remating and sperm competition in a terrestrial crustacean. Animal Behaviour, 64: 569-577.

Okumura, T., Han, C.-H., Suzuki, Y., Aida, K., \& Hanyu, I., 1992. Changes in hemolymph vitellogenin and ecdysteriod levels during the reproductive and non-reproductive molt cycles in the freshwater prawn Macrobrachium nipponense. Zoological Science, 9: 37-45.

Suzuki, S., 1987. Vitellins and vitellogenins of the terrestrial isopod, Armadillidium vulgare. Biological Bulletin, 173: 345-354.

- , 2001. Structural changes of the female genitalia during a reproductive cycle in the isopod crustacean, Armadillidium vulgare. Invertebrate Reproduction and Development, 40: 9-15.

- 2002. Reconstruction of the female genitalia at molting in the isopod crustacean, Armadillidium vulgare (Latreille, 1804). Crustacean Research, 31: 18-27.

— , Yamasaki, K., \& Katakura, Y., 1989. Vitellogenin synthesis by fat body and ovary in the terrestrial isopod, Armadillidium vulgare. General \& Comparative Endocrinology, 74: 120-126.

, Fujita, T., Mamiya, Y., \& Sonobe, H., 1996. Ovarian and hemolymph ecdysteroids in the terrestrial isopod Armadillidium vulgare (Malacostracan 
Crustacea). General \& Comparative Endocrinology, 104: 129-138.

-, \& Ziegler, A., 2005. Structural investigation of the female genitalia and sperm storage sites in the terrestrial isopod Armadillidium vulgare (Crustacea, Isopoda). Arthropod Structure and Development, 34: (in press).

Vandel, A., 1925. Recherches sur la sexualite des Isopodes. Les conditions naturelles de la reproduction chez les Isopodes terrestres. Bulletin Biologique de la France et de la Belgique, 59: 317-371.

Veuille, M., 1978. Biologie de la reproduction chez Jaera (Isopode Asellote). II. Evolution des organes reproducteurs femelles. Cahiers Biologie Marine, 19: 385-395.

Wägele, J.-W., 1990. Growth in captivity of the Antarctic fish parasite Aega antarctica (Crustacea, Isopoda). Polar Biology, 10: 521-527.

- , 1992. Isopoda. In: F.W. Harrison \& A.G. Humes (eds.), Microscopic Anatomy of Invertebrates, Volume 9, Crustacea, 529 - 617. Wiley and Sons, New York.

Warburg, M. R., 1993. Evolutionary Biology of
Land Isopods.159 pp. Springer-Verlag, Heidelberg.

Wilder, M. N., Okumura, T., Aida, K., \& Hanyu, I., 1991. Accumulation of ovarian ecdysteroids in synchronization with gonadal development in the giant freshwater prawn Macrobrachium rosenbergii. Zoological Science, 8: 919-927.

Wilson, G.D.F., 1984. The evolution of the janiroidean female reproductive apparatus (Crustacea, Isopoda, Asellota). American Zoologist, 24: 67.

- , 1986. Evolution of the female cuticular organ in the Asellota (Crustacea, Isopoda). Journal of Morphology, 190: 297-305.

- 1991. Functional morphology and evolution of isopod genitalia. In: R.T. Bauer \& J.W. Martin (eds.), Crustacean Sexual Biology, 228-245. Columbia University Press, New York.

Address: Kanagawa University of Human Services, Yokosuka 238-8522, Japan

E-mail: suzuki-sa@kuhs.ac.jp 